\title{
DISCLAIMER
}

This :eport was prepared as an account of work sponsored by an agency of the United States Government. Neither the United States Government nor any agency thereof, nor any of their employees, makes any warranty, express or implied, or assumes any legal liability or responsibility for the accurac $y$, completeness, or usefulness of any information, apparatus, product, or process disclosed, or represents that its use would not infringe privately owned rights. Reference herein to any specific commercial product, process, or service by trade name, trademark, manufacturer, or otherwise does not necessarily constitute or imply its endorsement, recommendation, or favoring by the United States Government or any agency thereof. The views and opinions of authors expressed herein do not necessarily state or reflect those of the United States Government or any agency thereof.

ANL/CP- -73551

DE91 015252

\section{STUDIES OF ION SOLVATION USING PULSE RADIOLYSIS*}

\author{
Charles D. Jonah and Yi Lin
}

Chemistry Division, Argonne National Laboratory, Argonne, IL 60439

\section{INTRODUCTION}

The understanding of solvation has always been a key component in understanding the chemistry that occurs after the irradiation of a polar liquid with ionizing radiation. It is competition between solvation and thermalization that determines the spatial distribution of ions and radicals.(1) This spatial distribution defines the amount of ion and radical recombination that competes with the reaction of radiation-produced species with other additives in a solution. The competition between solvation, thermalization and reaction determines the amount of the "dry electron" reaction (static scavenging).(2-5) Finally, solvation provides the energy for many reactions.(6) As an example the rates of electron transfer reactions depend on the solvation energy. For all of these reasons, solvation has been an important subject of study in radiation chemistry.

In previous work we studied the solyation of the electron in a series of alcohols.(7) These results suggested a correlation between the solvation time and $\tau_{2}$, the second dielectric relaxation time, which has been ascribed to the rotation of an alcohol molecule without breaking hydrogen bonds. (8) Results were suggestive of a two-state solvation mechanism in that the decrease in absorption measured by Hunt and coworkers at $1300 \mathrm{~nm}$ (9) correlated remarkably well with the solvation time measured at 500-600 nm.(7) However, the data of Hunt at $1000 \mathrm{~nm}$ are not so clear. Similar results have been obtained for the solvation of the electron in water where the decay of the precursor of the hydrated electron is very similar to the growth of the hydrated electron. $(10,11)$

The apparent two-state model for the solvated electron is not ubiquitous. Experiments in alcohols at lower temperatures $(12,13)$ and in glasses(14) strongly suggest a multi-stage process is occurring. For example n-propanol appears to show a simple two-state behavior above $130 \mathrm{~K}$, but at lower temperatures multistate behavior appears to dominate.(15) Multistate behavior is also seen in other alcohols. $(12,13,15)$ In fact even at room temperature in alcohols and in water, the processes appear to be more complex than simple two-state processes in that the absorption between the early time and the late time spectral maxima appears to be too large.(10)

In many ways, however, electron solyation may be an unusual process. Experimental data suggest that the eleciron solvation occurs in preformed traps, "density fluctuations", and thus the solvation process does not

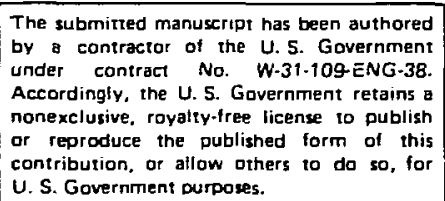


probe the solution as a whole, but instead samples only a subset of the solution. $(16,17)$ Thus conclusions about solvation drawn from electron solvation may not be general.

Because solvation is such an important field, there has been considerable study of the dynamics of solvation processes in other systems. For example considerable effort has been expended in studying the solvation of excited states of molecules.(18-21) In those studies, an aromatic molecule with large dipole moments was created by exciting the ground state molecule with light. The solvent was arranged around the newly created excited state to minimize the energy of the low dipole moment ground state. The solvent molecules would then rearrange to minimize the energy of the system including the high polarity excited state. The velocity of this rearrangement process was followed by measuring the change of the optical absorption spectrum.

Considerable work has been done in measuring the effect of solvation or of the solvent on optical absorption(22) although little work exists on the dynamics of ion solvation process. In this paper we describe our measurements of ion solvation in a series of alcohols. We use the system that was used by Hickel and coworkers at low temperatures.(23) Benzophenone is dissolved in an alcohol at a sufficiently high concentration so that the electrons formed by radiation will react with the benzophenone molecule to form the anion. The spectrum of the anion is then observed as a function of time. As the benzophenone anion solvates, the spectrum shifts to the blue.

The results of our measurements clearly show that both the size of the solvent molecules and their shapes are important in the solvation process. Different spectral relaxation processes are observed for ions than are observed for electron solvation, the "simple" ion system that has been most heavily studied. In addition, these results suggest that the rate of solvation may be different for ions in solution than for dipoles in solution.

\section{EXPERIMENTAL}

The Argonne stroboscopic pulse radiolysis system was used for these measurements. (24) Because this system has been described completely in the past, only a short summary of its capabilities will be given in the present publication. A $20-\mathrm{MeV}$ electron linac generates a short pulse of electrons (approximately $30 \mathrm{ps} \mathrm{FWHM).} \mathrm{Approximately} 30 \%$ of the electrons are intercepted by a cell filled with $1 \mathrm{~atm}$ of xenon to generate Cerenkov light for an analyzing light pulse. The remainder of the electrons are focussed into a $2 \mathrm{~cm}$ radiolysis cell (approximately $70 \mathrm{~Gy}$ ).

The solvents were either "distilled-in-glass" (Burdick and Jackson) or "spectroscopic" from Fisher Scientific and were used without further purification. Benzophenone was purchased from Aldrich (specified as 99+\%) and was used as received. Solvation experiments were run using .25 or $.5 \mathrm{M}$ benzophenone solutions, depending on the solubility. Experiments were also performed at $.05 \mathrm{M}$ benzophenone to observe the overlap of the electron spectrum with the benzophenone anion spectrum. Solutions were flowed through a suprasil cell to minimize radiation damage and the amount of radiation damage was shown to be minimal. All experiments have been done at room temperature. 


\section{RESULTS AND DISCUSSION}

Figure 1 shows the spectrum of the benzophenone anion at $50 \mathrm{ps}, 300$ ps and $3 \mathrm{~ns}$ in n-octanol solutions. The shift of the spectrum from the blue to the red is quite obvious. The absorption peak present at $550 \mathrm{~nm}$ has been assigned to the ketyl radical.(23) The characteristics of its formation appear to be quite interesting and the mechanism for it is unclear. However, we will not discuss this issue in this paper. Similar data have been published for the solvation of the benzophenone anion in n-decanol, where the solvation is slower.(25)

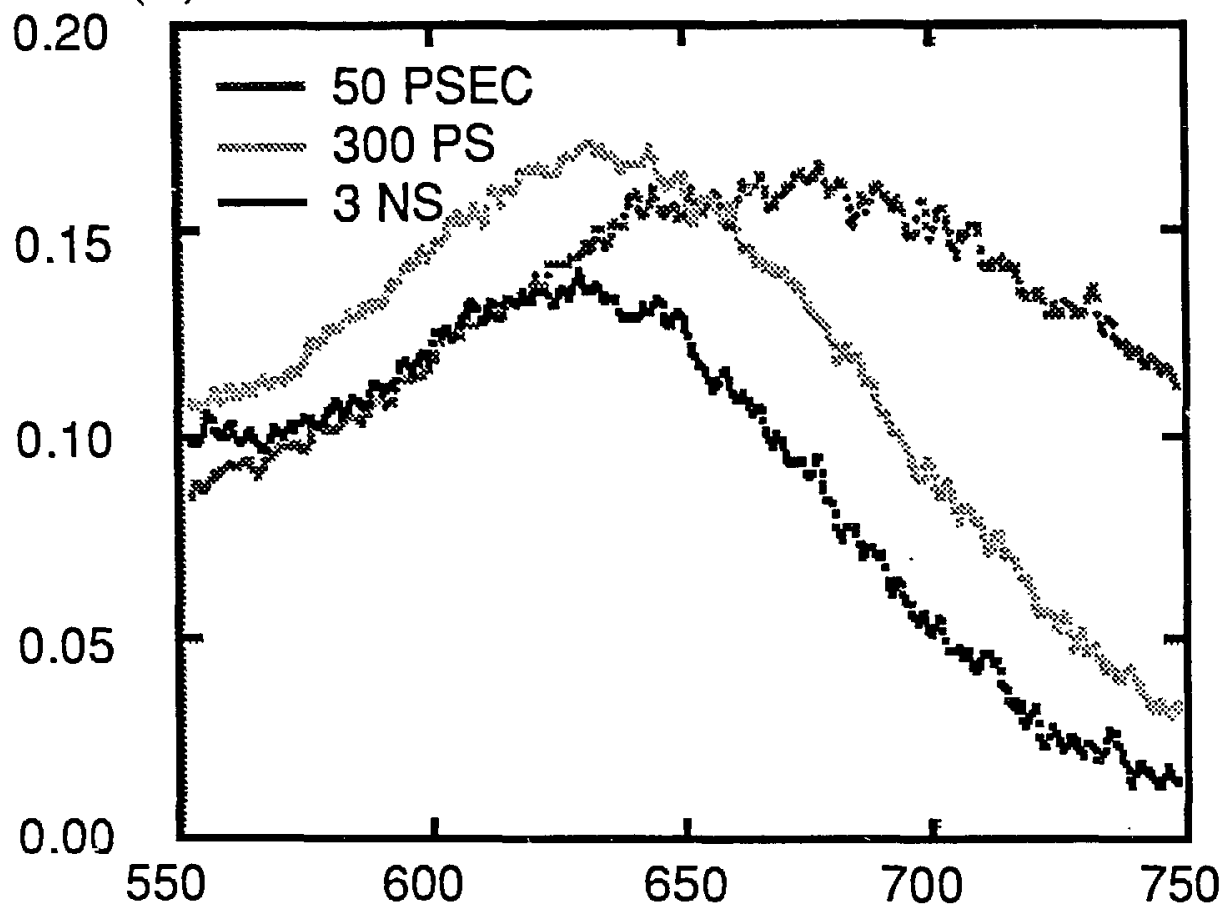

Figure 1: Absorption from the irradiation of $.15 \mathrm{M}$ benzophenone in n-octanol at $50 \mathrm{ps}, 300 \mathrm{ps}$ and $3 \mathrm{~ns}$ after the pulse. The absorption is assigned to the benzophenone anion.

The spectrum of the solvated electron would also overlap this spectrum. However, little solvated electron is formed in this system because the benzophenone reacts with the electron before its solvation. The overlapping electron has been seen when experiments are done using $.05 \mathrm{M}$ benzophenone rather than $.25 \mathrm{M}$ benzophenone. (It must be remembered that the yield of the solvated electron is exponentially decreasing as a function of the electron scavenger concentration so that the factor of 5 in concentration can make a large effect on the yield of the electron.)

One major difference between the behavior obtained for the benzophenone anion and the solvated electron is the shift in the spectrum. For the solvated electron, the spectrum is in the infrared and shifts to the visible. (9) 
However, for the benzophenone anion, the initial species is shifted from the final species by less than $100 \mathrm{~nm}$ rather than $500 \mathrm{~nm}$. This is because the electron must create its own localizing potential frorn the solvent molecules. For the benzophenone anion, the solvent acts only as a perturbation potential on the basic structure of the anion. In other words, the benzophenone anion would exist in the gas phase without the solvent; the solvated electron would not exist without the solvent.

The importance of the exact structure of the soivent can be seen in Figure 2. The shift of the spectrum of the benzophenone anion in 2-octanol is smaller than in the n-octanol and the final spectrum is red-shifted from what is observed in the normal alcohol. This result is not surprising because it is more difficult for the secondary alcohol. The methyl group near the solvating hydroxyl group interferes with the solvation. It is important to note that the position of the spectrum and the amount of shift is virtually independent of chain length for a primary alcohol.

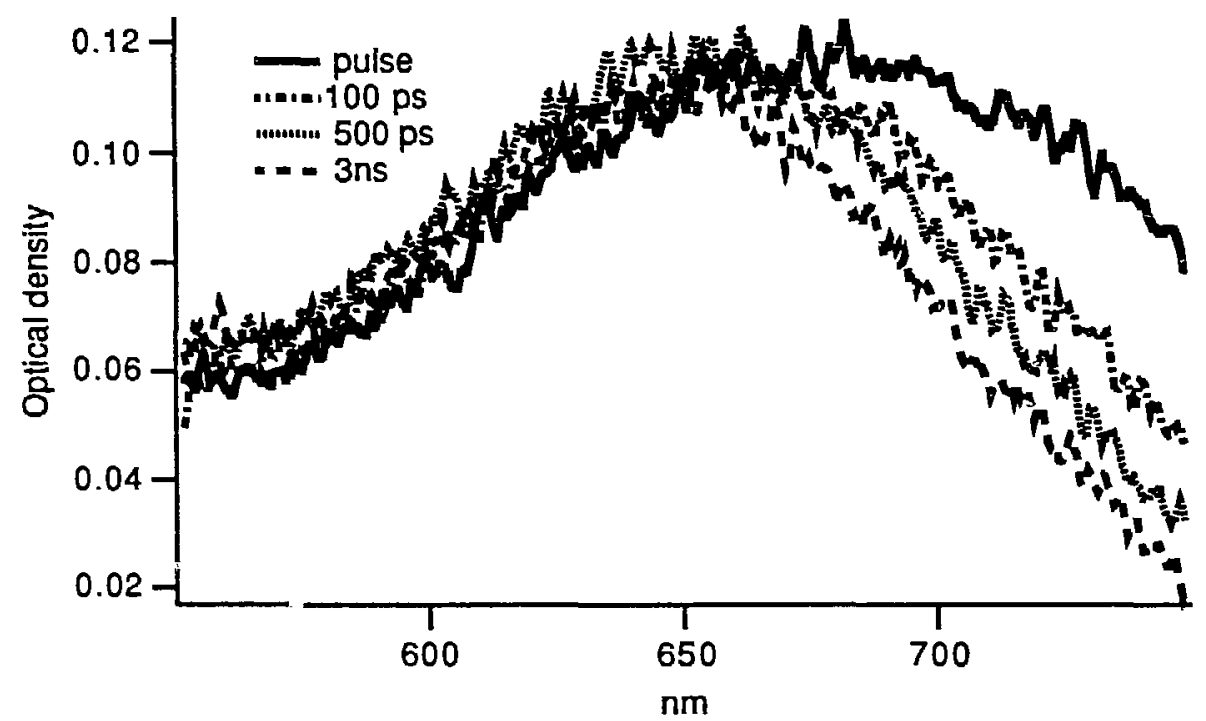

Figure 2: The absorption spectrum of benzophenone anion in 2-octanol.

The effect of structure is even greater on the solvated electron. The maximum of the solvated electron is strongly shifted to the red in 2-butanol or 2-octanol. $(7,26)$ The difference in the amount of shift between primary and secondary alcohols and the way this difference changes between benzophenone and the solvated electron is consistent with the previous discussion

As has been mentioned earlier, electron solvation appears to be fairly well described by a two-state model.(7,9-11) In such a model, an initial species relaxes to a final species. This means that the kinetics are similar at all wavelengths. In benzophenone, however, the kinetics depend strongly on wavelength as is seen in Figure 3. Similar results have been obtained in decanol where the solvation time of the anion (as measured by the decay of the absorption) appears to be $80 \mathrm{ps}$ when measured at $800 \mathrm{~nm}$ or $110 \mathrm{ps}$ when 
measured at $750 \mathrm{~nm}$.(25) These can be compared to the solvation time of the electron measured at 600 of $60 \mathrm{ps}$. Further, there appears to be both a growth and decay at $650 \mathrm{~nm}$. This could not occur if relaxation were a two-state process.

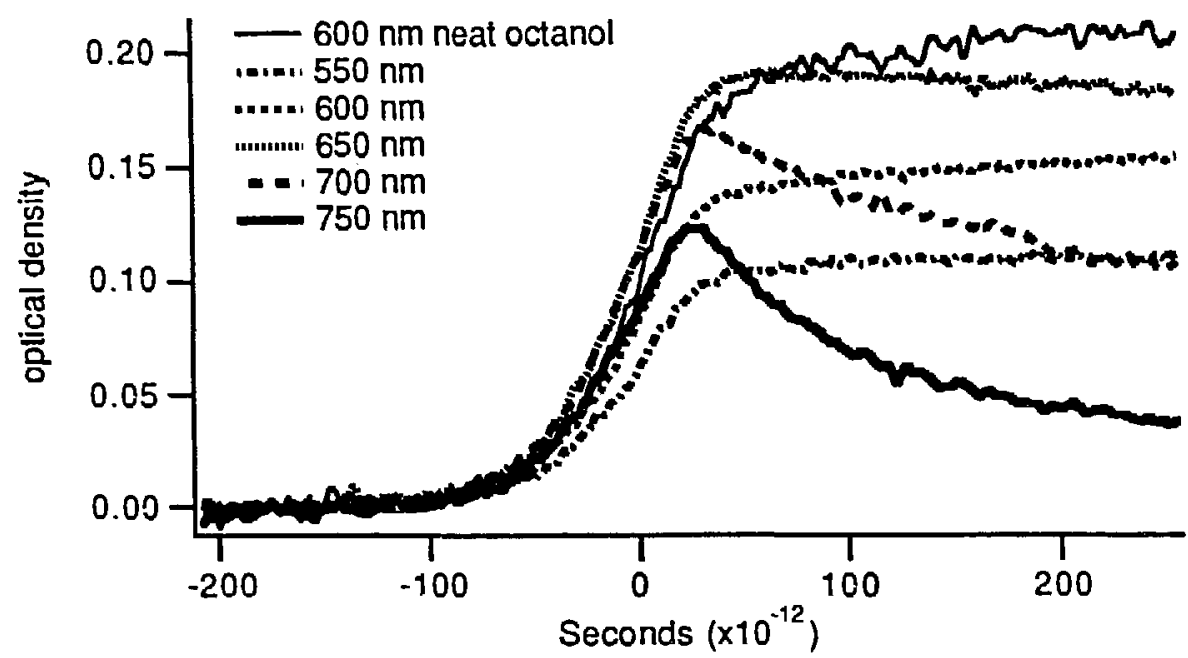

Figure 3: Absorption kinetics for .25 $\mathrm{M}$ benzophenone in $\mathrm{n}$-octanol except for the neat octanol trace that is given as reference.

The solvation of the electron occurs from a special site within the solution, a site that must be favorably arranged to lower the energy of the electron, otherwise it wouldn't trap the electron. However, the solvent around the benzophenone anion is initially arranged to minimize the energy of the neutral molecule rather than the charged species. Thus the orientation of the solvent molecules may be closer to final configuration around an electron and thus the solvation would take less time for the electron. This is indeed what we see.

Other experiments that we have not discussed here include experiments in acetonitrile. In acetonitrile, the solvation appears to be slow and the spectrum does not changed strongly as a function of time.(26)

\section{SUMMARY}

The solvation of the benzophenone anion has been measured in several alcohols. The solvation process goes through multiple intermediate states that have some lifetime on the picosecond time scale rather than through what appears to be only two states in alcohols

\section{REFERENCES}

* Work performed under the auspices of the Office of Basic Energy Sciences, Division of Chemical Science, US-DOE under contract number W-31-109-ENG-38.

1. C. D. Jonah and A. C. Chernovitz, Can. J. Phys. 68, 935-939 (1990). 
2. W. H. Hamill, J. Phys. Chem. 73, 1341 (1969); H. Ogura and W. H. Hamill, J. Phys. Chem. 78, 504 (1974).

3. J. W. Hunt and W. J. Chase, Can J. Chem. 55, 2080 (1977).

4. K. Okazaki and G. R. Freeman, Can J. Chem. 56, 2313 (1978).

5. C. D. Jonah, J. R. Miller and M. S. Matheson, J. Phys. Chem. 81, 1618 (1977).

6. I. Rips, J. Klafter and J. Jortner, J. Chem. Phys. 88, 3246(1988).

7. G. A. Kenney-Wallace and C. D. Jonah, Chem. Phys. Lett. 39, 596(1976); J. Fhys. Chem. 86, 2572-_ (1982).

8. S. K. Garg and C. P. Smyth, J. Phys. Chem. 69, 1294-

9. W. J. Chase and J. W. Hunt, J. Phys. Chem. 79, 2835-

10. A. Migus, Y. Gauduel, J. L. Martin, and A. Antonetti, Phys. Rev. Lett. 58, 1559(1987).

11. F. H. Long, H. Lu and K. B. Eisenthal, J. Chem. Phys. 91, 4193(1989).

12. L. Gilles, M. R. Bono and M. Schmidt, Can. J. Chem. 55, 2003(1977).

13 K. Okazaki and G. R. Freeman, Can J. Chem. 56, 23uj(1978).

14. L. Kevan, J. Phys. Chem. 84, 1232-___ (1980), Acct Chem Res. $14,138-$ (1980).

15. J. H. Baxendale and P. Wardman, J. Chem. Soc. Fraday Trans I 69, $584-$ (1973).

16. G. A. Kenney-Wallace and C. D. Jonah, Chem. Phys. Lett. 47, 362(1977).

17. J. Jortner and A. Gaathon, Can.J. Chem. 55, 1801-

18. Y. Wang, M. McAuliffe, F. Novak, and K. B. Eisenthal, J. Phys. Chem. 85, 3736(1981).

19. D. Huppert, S. D. Rand, P. M. Rentzepis, P. F. Barbara, W.S. Struve and Z. R. Grabowski, J. Chem. Phys. 75, 5714(1981).

20. M. Maroncelli and G. R. Fleming, J. Chem. Phys. 86, 622(1987).

21. S. G. Su and J. D. Simon, J. Chem. Phys. 89, 809(1988).

22. C. Reichardt, Solvents and Solvent Effects in Organic Chemistry, VCH, Weinheim, Germany, 1988.

23. J. L. Marignier and B. Hickel, Chem. Phys. Lett. 86, 95-_ (1982); J. Phys. Chem. 88, 5375-__ (1984).

24. C. D. Jonah. Rev. Sci. Instrum. 46, 62-_(1975).

25. Yi Lin and C. D. Jonah, Submitted Chem. Phys Lett.

26. Yi Lin and C. D. Jonah, to be published. 